\title{
Estrutura de Serviços de Varejo nas Redes de Hospedagem Brasileiras
}

\author{
Structure of Retail Services in the Brazilian Hosting Network
}

\section{Estructura de Servicios de Minoristas en la Red de Alojamiento Brasilenõ}

\author{
Claudio Zancan ${ }^{1}$ \\ Anderson de Barros Dantas ${ }^{2}$ \\ Vanessa Oliveira Campos ${ }^{3}$
}

\begin{abstract}
Resumo: esta pesquisa identificou as redes de hospedagem brasileiras por meio de indicadores da infraestrutura de serviços comercializados nos estabelecimentos turísticos que formam essas redes. A teoria consultada compreendeu a discussão das técnicas estruturais presentes na Análise de Redes Sociais. O estudo apresentou três etapas: pesquisa documental, criação de bancos de dados e entrevistas. Os resultados identificaram três redes de hospedagem no Brasil com maior expressão, formadas por hotéis, pousadas e resorts. Foram verificadas características diferenciadas de infraestrutura e de serviços comercializados entre elas. Estudos futuros sugerem a análise comparativa de indicadores estruturais presentes em outros segmentos de serviços turísticos, bem como, a influência internacional existente no desenvolvimento das redes turísticas brasileiras.
\end{abstract}

Palavras-chave: Redes de hospedagem. Inovação no turismo. Estrutura de hospedagem brasileira.

Abstract: this research has identified Brazilian hosting networks through infrastructure services indicators that it was sold to tourists in organizations that form these networks. The theory consulted the discussion of structural techniques present in Social Network Analysis. The study has three stages: documental research, creation of Tourism database and interviews. The results identified three networks with the highest expression in Brazil formed by hotels, lodges, and resorts. Different characteristics of infrastructure and services were observed between hosting networks. Future studies suggest a comparative analysis of structural indicators present in other segments of tourism services, as well as the existing international influence on the development of the Brazilian hosting networks.

Keywords: Hosting networks. Tourism innovation. Structure of Brazilian hosting.

Resumen: esta investigación ha identificado las redes de acogida de Brasil a través de indicadores de los servicios de infraestructura que se venden en los establecimientos turísticos que forman estas redes. La teoría consultado incluyó la discusión de las técnicas estructurales presentes en el Análisis de Redes Sociales. El estudio consta de tres etapas: investigación documental, la creación de la base de datos Turismo y entrevistas. Los resultados identificaron tres redes de alojamiento en Brasil, con la expresión más alta formada por hoteles, cabañas y resorts. Se observaron diferentes características de la infraestructura y los servicios que se comercian entre ellos. Futuros estudios sugieren un análisis comparativo de los indicadores estructurales presentes en otros segmentos de los servicios turísticos, así como la influencia internacional existente relativa al desarrollo de las redes turísticas brasileñas.

Palabras-clave: Redes de alojamento. La innovación en el turismo. Lla estructura de alojamiento de Brasil.

1 Professor da Universidade Federal de Alagoas (UFAL), Brasil. E-mail: claudiozancan@gmail.com

2 Professor da Universidade Federal de Alagoas (UFAL), Brasil. E-mail: anderson.admead@gmail.com

3 Especialista e Pesquisadora em Gestão Pública, Brasil. E-mail: vanessaoczancan@gmail.com 


\section{INTRODUÇÃO}

O turismo se caracteriza como atividade de integração sociocultural, promovendo o intercâmbio de diferentes culturas e o estreitamento das relações entre as sociedades, com relevantes contribuições para a geração de renda e emprego. Por meio do turismo, o país ou região divulga suas paisagens, tradições, gastronomia, hábitos, modos de vida, sua cultura em geral, contribuindo para a preservação dos patrimônios arquitetônico e ambiental, bem como para a difusão de sua imagem, em níveis intranacional e internacional. O turismo, assim, gera um círculo virtuoso e contribui para o desenvolvimento sustentável.

O Brasil é reconhecido como um país com grandes potencialidades turísticas, devido, principalmente, a sua extensão territorial, que oferece, no âmbito do turismo de lazer, destinos bastante diversificados, como praias, montanhas, áreas rurais e selva. Todos esses destinos são atrativos para o desenvolvimento do ecoturismo, do turismo rural e do turismo voltado para esportes radicais, aliando-se lazer e prática de esportes com preservação ambiental. Porém, a existência de inúmeros recursos naturais e a cultura receptiva brasileira, por si só, não se constituem em razões suficientes para a expansão desta atividade econômica como ocorre em outros contextos. É necessário algo mais.

Entre as possibilidades de expansão e fortalecimento deste setor econômico no Brasil temse a formação de estruturas interorganizacionais orientadas no compartilhamento de riscos e investimentos como opção estratégica. Estudos recentes no setor de turismo, entre eles: Hammersley (2014), Zehrer (2014), Zimanyi e Kozar (2014), Bock e Macke (2014), Carmona, Costa e Ribeiro (2014), Wu e colaboradores (2012), Pinto e Cruz (2012), Kwon, Kim e Yi-Kook (2011), Ivanov (2011), comprovam a importância deste tipo de estrutura organizacional como alternativa capaz de propiciar a geração de resultados superiores para o desenvolvimento dos países.

$\mathrm{Na}$ tentativa de contribuir nesta direção, esta pesquisa se insere no âmbito de estudos que objetivam identificar a importância que as características estruturais de redes interorganizacionais representam para o desenvolvimento de atividades no setor turístico brasileiro. Especificamente, aquelas características presentes nos relacionamentos estabelecidos entre organizações que prestam atividades de hospedagem no Brasil. Teoricamente, está preocupação é pertinente, pois, apesar da importância destacada na literatura para as estruturas das redes interorganizacionais como indutoras de estratégias inovadoras em setores econômicos tradicionais, ainda pairam dúvidas sobre elementos que promovem a consecução dessas estratégias no contexto interorganizacional de serviços.

Em termos práticos, esta pesquisa traz aos pesquisadores da área do Turismo, bem como, para outros interessados no tema, a verificação de assuntos correlacionados a temática: redes interorganizacionais, contribuindo assim, para o desenvolvimento desse conceito no setor de turismo brasileiro. Além disso, a importância estratégica que o conhecimento dos indicadores estruturais proporciona para os gestores envolvidos na direção das organizações inseridas nesse setor é fator vital quando se objetiva o desenho de políticas de investimentos públicos e privados efetivas 
voltadas a geração de inovação. Em tempos de grande competitividade, todo o conhecimento do contexto social em que uma organização está inserida não pode passar despercebido e, os indicadores estruturais de redes, configuram-se como ferramenta analítica no auxílio da interpretação destas informações.

Assim, o objetivo geral desta pesquisa é: identificar as redes de hospedagem brasileiras por meio de indicadores da infraestrutura de serviços comercializados nos estabelecimentos turísticos que formam essas redes. Destaca-se que o cenário de estudo adota como base de observação as organizações registradas no Sistema de Cadastro de Pessoas Físicas e Jurídicas que atuam no Setor do Turismo (CADASTUR), gerido pelo Ministério do Turismo. Este sistema registra o cadastro de organizações de turismo dos 26 estados brasileiros e no Distrito Federal, sendo que neste estudo, tem-se a presença de 6396 organizações com atividades de hospedagem, divididas nas seguintes categorias: hotéis, pousadas, hotel-fazenda, hotel histórico, cama \& café, flat e resort (Cadastur, 2014).

Para atender o objetivo principal aqui proposto - identificar as redes de hospedagem brasileiras por meio de indicadores da infraestrutura de serviços comercializados nos estabelecimentos turísticos que formam essas redes - foram utilizadas três etapas nessa pesquisa: pesquisa documental (análise de sítios eletrônicos), criação de um banco de dados com base nas informações oficiais disponibilizadas no Sistema de Cadastro de Pessoas Físicas e Jurídicas (CADASTUR) e entrevistas.

\section{UMA VISÃO GERAL DA ANÁLISE DE REDES SOCIAIS (ARS)}

Os primórdios da Análise de Redes Sociais (ARS) nas Ciências Sociais remontam aos anos de 1920 em estudos da Psicologia Social (FREEMAN, 1996). Essas pesquisas investigavam como o contexto social e o padrão de relacionamentos, influenciavam o comportamento individual de crianças pré-escolares nos Estados Unidos. Porém, a comunidade científica, geralmente, data a origem da abordagem da ARS com a publicação do livro Who shall survive do sociólogo Jacob Moreno, em 1934, e por meio da criação da Revista Sociometry, em 1937 (Carrington e colaboradores, 2005).

A partir de então três vertentes de conhecimento teriam fundamentado a abordagem de ARS: a) os analistas sociométricos, que em 1930 trabalharam em pequenos grupos e produziram avanços técnicos com métodos da teoria dos grafos; b) os pesquisadores de Harvard, que também nos anos de 1930 exploraram padrões de relações interpessoais informais e a formação de subgrupos, e; c) os antropólogos de Manchester, que usaram os conceitos das duas primeiras vertentes para investigar a estrutura de relações comunitárias em sociedades tribais e pequenas vilas. Essas três correntes foram reunidas novamente em Harvard nas décadas de 1960 e 1970, quando foram forjadas as bases da atual teoria de ARS (Scott, 2000).

De acordo com Martes e colaboradores (2006, p.34), "no âmbito dos estudos organizacionais, a perspectiva de Redes Sociais emergiu no final dos anos de 1970, quando autores como Aldrich e Williamsom passaram a tomar a forma de relacionamento interorganizacional como foco 
de análise". A influência desses autores fez com que este tema chegasse aos primeiros anos da década de 1990, sendo percebido sob três enfoques na literatura organizacional. O primeiro enfoque considerava as redes como um novo arranjo voltado à melhoria do desenho organizacional. 0 segundo enfoque estava voltado para a análise do processo de formação e estruturação de arranjos cooperativos. Por fim, o terceiro enfoque compreendeu os relacionamentos organizacionais em redes a partir de uma perspectiva temporal mais ampla.

No início dos anos 2000, no cenário internacional, publicações sobre este tema ganharam notoriedade, por exemplo, em 2004, o Academy Journal lançou uma edição especial sobre redes interorganizacionais. Nessa edição especial tem-se, entre outros, publicações de Bae e Gargiulo (2004), Gibbons (2004), Gimeno (2004). Esses trabalhos, de forma geral, enfatizam aspectos relacionados ao desenvolvimento das estruturas das redes como estratégia de evolução de relacionamentos interorganizacionais. Além disso, tais estudos propuseram um conjunto de frameworks, objetivando a consolidação do tema e a orientação de futuras abordagens em torno da discussão relacionada com a definição de antecedentes e consequentes na formação das redes.

No Brasil, são encontradas as primeiras evidências da utilização das técnicas de ARS, na ciência administrativa, em um artigo publicado na Revista de Administração de Empresas (RAE) em 1984, de autoria de Reed Nelson. Nesse texto, Nelson (1984) discutiu questões metodológicas que abordavam a modelação de blocos sociais (blockmodeling) no estudo de estruturas organizacionais. No entanto, a publicação efetuada por esse autor se constituiu como uma replicação do estudo efetuado por White, Boorman e Breiger, da Universidade de Harvard, que se basearam no princípio que as semelhanças nas estruturas das redes individuais são mais importantes do que as ligações reais entre pessoas no estudo da estrutura social (Nelson, 1984).

Em dias atuais, no Brasil, esta situação mudou. O interesse na aplicação da perspectiva de redes no contexto dos estudos organizacionais teve um aumento significativo na quantidade e qualidade de pesquisas produzidas. Entre outras evidências desse maior interesse sobre o tema tem-se o volume 43 da Revista de Administração Pública (RAP) em 2009, bem como o volume 46 da Revista de Administração de Empresas (RAE) em 2006. Ambos os periódicos, nesses volumes, adotaram a temática de redes como eixo principal de suas publicações. Além disso, eventos produzidos sob a coordenação da Associação Nacional de Pós-Graduação e Pesquisa em Administração (ANPAD) passaram, a partir de 2011, contar com essa área temática em seis de suas divisões: Administração da Informação, Administração Pública, Estudos Organizacionais, Estratégia em Organizações, Gestão de Ciência, Tecnologia e Inovação e Gestão de Operações Logísticas, demonstrando dessa forma, crescimento significativo de interesse do tema no campo da Administração no Brasil.

De forma geral, os resultados das pesquisas produzidas no Brasil sobre o enfoque temático de redes podem ser percebidos em dois grupos. No primeiro grupo de resultados, as redes são investigadas como alternativas estratégicas para a sobrevivência organizacional, revelando resultados que configuram tipos inovadores de alianças entre organizações (ou grupo de organizações), ganhando notoriedade por combinar eficácia, informalidade e flexibilidade no gerenciamento dos 
relacionamentos interorganizacionais desenvolvidos. No segundo grupo de resultados, estão situados aqueles estudos que consideram como objetivo a aplicação das técnicas de ARS, ou seja, preocupam-se na demonstração de resultados que revelam padrões estruturais dos relacionamentos organizacionais estabelecidos em forma de rede.

É com base neste segundo grupo de resultados que este artigo tem seu objetivo principal definido porque a importância da visão macro dos relacionamentos interorganizacionais estabelecidos no setor turístico brasileiro constitui o estabelecimento uma estrutura inicial de análise desse setor sob a ótica da Análise de Redes Sociais. Portanto, na próxima seção do texto, são apresentados alguns dos indicadores estruturais que permitem definir a estrutura de uma rede de relacionamentos por meio da aplicação da metodologia de Análise de Redes Sociais no Setor de Turismo Brasileiro.

\section{TÉCNICAS ESTRUTURAIS DA ANÁLISE DE REDES SOCIAIS}

Embora a aplicação do conceito de Redes Sociais represente uma preocupação quase secular à academia internacional (Freeman, 1996), é verificada na literatura a ausência de um delineamento metodológico padrão nas pesquisas que se utilizam dessa perspectiva. Nesta direção, Tichy, Tuschman e Fombrum (1979) buscaram sintetizar as propriedades das redes e destacaram três como principais: conteúdo transacional, natureza das ligações e características estruturais. Essa última propriedade, envolvendo as técnicas de Análise de Redes Sociais, inclusive, identificada com componentes específicos: tamanho, densidade, clustering, abertura, estabilidade, reachability, centralidade, estrela, liaison, ponte, gatekeeper e isolado.

Da mesma forma, Wassermann e Faust (1994) argumentam que as aplicações dos conceitos relacionados na Análise de Rede Sociais (ARS) podem ser categorizadas por: a) medidas estruturais (como as medidas de centralidade, densidade, transitividade e coesão); b) papéis e posições (como a análise de equivalência estrutural, regular, análise de clusters e de blockmodels), e; c) análise estatística dos relacionamentos (utilizadas com o objetivo de testar proposições teóricas acerca das propriedades relacionais).

$\mathrm{Na}$ literatura de ARS alguns estudos servem como base de fundamentação das categorias propostas por Wasserman e Faust (1994). O trabalho que aborda o conceito de centralidade de rede proposto por Freeman (1979), constitui-se como um exemplo. Segundo esse autor, a centralidade de uma rede pode ser dividida em três categorias básicas: a) centralidade de grau (mensurada pelo número de laços que um ator possui com outros atores da rede); b) centralidade de proximidade (baseada na proximidade ou distância de um ator em relação aos outros atores em uma rede) e; c) centralidade de intermediação (referente às ligações intermediárias que conectam outros atores que não estão conectados diretamente). A perspectiva do conceito de centralidade de Freeman (1979) tornou-se alvo de interesse de pesquisas no cenário internacional (Everett \& Borgatti, 2005), inclusive no Brasil, (Pinto \& Junqueira, 2009; Rossoni \& colaboradores, 2008). 
Como extensão do conceito de centralidade proposto por Freeman (1979), Everett e Borgatti (2005) propuseram o estudo da centralidade de grupos, categorizando as medidas estruturais da seguinte forma: a) centralidade de grau de grupos (definida como o número de atores fora do grupo central que estão conectados com aqueles que possuem maior centralidade); b) centralidade de proximidade de grupos (compreendendo a soma inversa normalizada das distâncias entre o grupo central e todos os outros atores fora do grupo central) e; c) centralidade de intermediação de grupos (mensurada pela proporção geodésica de pares conectados de membros que estão fora do grupo central e que passam através deste).

Everett e Borgatti (2005) ainda afirmaram que por meio do modelo proposto é mensurada uma medida efetiva de formação de capital social dos grupos sociais. Nesta direção, Lin (2008) desenvolve uma teoria de redes baseada no capital social e com centralidade nos padrões das relações sociais, que variam em intensidade e reciprocidade dos laços. Para Lin (2008), três dimensões das relações sociais mudam de intensidade e reciprocidade em redes: interna (relações próximas e de confiança, laços de compartilhamento de sentimentos e apoio mútuos), intermediária (laços em que geralmente ocorre o compartilhamento de recursos e informação) e externa (relações de identidade compartilhadas, ainda que os membros possam não interagir entre si).

Outro conceito aplicado nos estudos que envolvem a ARS que merece ser destacado é o da coesão social. Nesse sentido, vale destacar o modelo proposto por Wasserman e Faust (1994) que define as seguintes propriedades no estudo de subgrupos coesos dentro de uma rede social: a) mutualidade de laços, definida como até que ponto todas as escolhas dos atores em um subgrupo são mútuas, formando cliques entre atores e b) proximidade e alcance entre membros dos subgrupos.

Esta propriedade é definida levando em consideração os intermediários do processo social, formalizando o conceito de $n$-clique ( $n$-clique significa um subgrupo em que a maior distância geodésica entre dois nós é igual ou menor a $n$, no qual $n$ é o caminho máximo em que membros de um clique podem estar conectados); c) frequência de laços entre membros é definida na abordagem de Scott (2000) como k-plexes, ou seja, um subgrafo em que cada nó é adjacente a todos os nós, exceto a $K$ outros pontos e; d) frequência relativa de laços entre membros de fora e de dentro dos subgrupos, definida como a comparação da coesão relativa entre membros de fora e de dentro dos subgrupos. Essa propriedade é mensurada por duas medidas: a LS Sets, definida por Seidman (1983) como um conjunto de nós, com cada nó apresentando mais laços entre os participantes desse conjunto do que com participantes de fora, e a Lambda Set, definida por Wasserman e Faust (1994) como um conjunto de nós, sendo que alguns desses nós apresentam conectividade de linha com algum nó de fora do Lambda Set.

No que tange aos estudos que analisam papéis e posições dos atores nas Redes Sociais, alguns autores ganham destaque na literatura (Scott, 2000; Wasserman \& Faust, 1994; Everett \& Borgatti, 2005). De acordo com Wasserman e Faust (1994) o conceito de posição se refere a um grupo de atores que estão similarmente imersos em uma rede de relações, sendo que o conceito de papel se refere com características das relações obtidas entre atores e posições. Rossoni e co- 
laboradores (2008) argumentam sobre dois aspectos centrais na análise de papéis e posições, que são: identificar as posições sociais como coleções de atores que são similares em seus laços por meio da equivalência estrutural e da equivalência regular e, modelar papéis sociais como sistemas de laços entre atores ou entre posições contando com métodos de blockmodels e de álgebra relacional.

O quadro a seguir sintetiza os pontos observados nesta seção do texto, permitindo com isso, uma visão geral das principais técnicas de Análise de Redes Sociais utilizadas nos estudos mencionados. Ressalta-se que os pontos relacionados, bem como os autores utilizados para referencialos não constitui o total das publicações efetuadas sobre o tema. No entanto, as técnicas de ARS demonstradas apresentam uma estrutura geral que pode ser evidenciada na maioria dos estudos que envolvem a aplicação de ARS.

Quadro 1 -Técnicas de Análise de Redes Sociais

\begin{tabular}{|c|c|c|}
\hline Técnicas de ARS & Derivações do conceito & Autores analisados \\
\hline $\begin{array}{l}\text { Medidas Estrutu- } \\
\text { rais }\end{array}$ & $\begin{array}{l}\text { Centralidade de grau de entrada e saída, proximida- } \\
\text { de e intermediação, para atores e grupo de atores, } \\
\text { densidade da rede, transitividade e coesão social (n- } \\
\text { clique, k-plexex, LS Sets e Lambda Set. }\end{array}$ & \multirow{3}{*}{$\begin{array}{l}\text { Freeman (1979), Hanneman } \\
\text { (2001), Hanneman e Riddle } \\
\text { (2005), Scott (2000), Wasser- } \\
\text { mann e Faust (1994), Everett e } \\
\text { Borgatti (2005), Pinto e Jun- } \\
\text { queira (2009), Rossoni, Hoca- } \\
\text { yen da Silva e Ferreira Jr } \\
\text { (2008). }\end{array}$} \\
\hline Papéis e $P$ & $\begin{array}{l}\text { Equivalência Estrutural, Equivalência Regular, Análise } \\
\text { de Clusters e Análise de Blockmodels. }\end{array}$ & \\
\hline Análise & $\begin{array}{l}\text { Estatísticas descritivas uni e multivariadas sobre } \\
\text { características dos atores ou grupos. }\end{array}$ & \\
\hline
\end{tabular}

Fonte: Elaborado pelos autores

Após a apresentação do contexto de origem e utilização das técnicas oriundas da Análise de Redes Sociais (ARS), com a finalidade de analisar as redes brasileiras de hospedagem por meio de medidas estruturais, são especificados os procedimentos metodológicos deste estudo.

\section{MÉTODO}

Esse estudo é classificado como descritivo-comparativo, o nível de análise utilizado foi o de redes e a unidades de análise, os serviços comercializados nos estabelecimentos de hospedagem brasileiros que constavam registrados no CADASTUR até 20 de abril de 2014. Ao todo foram considerados 6396 (seis mil trezentos e noventa e seis) estabelecimentos turísticos, classificados como: pousadas, hotéis, hotel-fazenda, hotel histórico, cama \& café, flat, resorts e outros (albergues, alojamento em florestas e hospedarias). O número dos estabelecimentos turísticos analisados por região política brasileira é apresentado a seguir: 
Quadro 2 - Estabelecimentos turísticos analisados

\begin{tabular}{|c|c|c|c|c|c|}
\hline Regiões & Sul & Centro-Oeste & Sudeste & Nordeste & Norte \\
\hline Pousadas & 256 & 268 & 476 & 741 & 111 \\
\hline Hotéis & 970 & 876 & 1011 & 774 & 527 \\
\hline Hotel fazenda & 10 & 28 & 0 & 0 & 5 \\
\hline Hotel histórico & 0 & 2 & 0 & 0 & 1 \\
\hline Cama \& Café & 8 & 29 & 0 & 0 & 7 \\
\hline Flat & 68 & 27 & 0 & 0 & 10 \\
\hline Resort & 12 & 3 & 32 & 60 & 2 \\
\hline Outros & 30 & 15 & 0 & 0 & 37 \\
\hline TOTAL & $\mathbf{1 3 5 4}$ & $\mathbf{1 2 4 8}$ & $\mathbf{1 5 1 9}$ & $\mathbf{1 5 7 5}$ & $\mathbf{7 0 0}$ \\
\hline
\end{tabular}

Fonte: CADASTUR (2014)

Para a análise dos dados obtidos nos sítios eletrônicos consultados na pesquisa documental (Ministério do Turismo e do SEBRAE Nacional), bem como do banco de dados criado com base em informações extraídas do CADASTUR, após uma análise detalhada das informações encontradas, as mesmas foram agrupadas e resumidas em três categorias: o turismo no cenário nacional, o sistema hoteleiro brasileiro e a infraestrutura de serviços comercializada nos estabelecimentos turísticos brasileiros. É válido ressaltar que por motivos de espaço, nesse artigo é apresentada uma síntese das informações encontradas no terceiro tópico que envolveu aspectos pontuais da infraestrutura dos serviços comercializados.

Na realização das entrevistas, foram ouvidos 15 (quinze) gestores estratégicos dos estabelecimentos turísticos analisados, entre os meses outubro e dezembro de 2013. As organizações entrevistadas foram escolhidas de forma aleatória com base na região política, estado geográfico de localização e categoria de hospedagem, dentre as categorias mais representativas em termos quantitativos dos estabelecimentos analisados (hotéis, pousadas e resorts). As questões efetuadas estiveram relacionadas com a infraestrutura de serviços oferecidos, relacionamentos mantidos entre as organizações registradas no CADASTUR, além de possibilidades de cooperação entre essas organizações. O quadro a seguir relaciona a organização entrevistada, o cargo dos entrevistados e o tempo de duração das entrevistas.

Para a análise dos dados obtidos nas entrevistas, juntamente com informações provenientes da pesquisa documental, foram aplicadas as técnicas estruturais provenientes da Análise de Redes Sociais com o intuito de formar redes por categoria de hospedagem entre as organizações registradas no CADASTUR a partir de semelhanças encontradas nos serviços de hospedagem oferecidos (estacionamento, restaurante, bar, manobrista, disponibilização de informações e folhetos turísticos, banheiros sociais em áreas comuns e elevador). Dessa maneira, foi mapeada uma rede para as três categorias de hospedagem com maior número de organizações em operação - hotéis, pousadas e resorts - sendo verificados os seguintes indicadores estruturais: densidade da rede, quantidade de subgrupos, centralidade de grau de entrada, saída, proximidade e intermediação, além de estatísticas descritivas. O total dos empreendimentos analisados nessas categorias foi 6119, sendo 4158 hotéis, 1852 pousadas e 109 resorts. 
Quadro 3 - Dados das entrevistas

\begin{tabular}{|c|l|l|l|c|}
\hline $\begin{array}{c}\text { Categoria de } \\
\text { Hospedagem }\end{array}$ & Organização entrevistada & Região/UF & Cargo & $\begin{array}{c}\text { Duração } \\
\text { Minutos }\end{array}$ \\
\hline Hotel & Costão do Santinho Turismo e Lazer & Sul/SC & Gerente Marketing & 92 \\
\hline Hotel & Rio Othon Palace Hotel & Sudeste/RJ & Gerente Geral & 48 \\
\hline Hotel & Hotel Hilton Belém & Norte/PA & Gerente de Vendas & 66 \\
\hline Hotel & Sauipe Park & Nordeste/BA & Relações Públicas & 84 \\
\hline Hotel & Hotel Golden Dolphin Resort & Centro-oeste/GO & Gerente Geral & 60 \\
\hline Pousada & Summer Beach Turismo & Sul/SC & Proprietário & 86 \\
\hline Pousada & Pousada Duas Praias & Sudeste/RJ & Proprietário & 56 \\
\hline Pousada & Pousada Nova Vida & Norte/RO & Gerente Geral & 64 \\
\hline Pousada & Pousada Sauipe & Nordeste/BA & Proprietário & 85 \\
\hline Pousada & Pousada Real & Centro-oeste/MT & Proprietário & 53 \\
\hline Resort & Mabu Thermas \& Resort & Sul/PR & Gerente Geral & 84 \\
\hline Resort & Alphalinas Turismo Ltda & Sudeste/SP & Gerente Marketing & 64 \\
\hline Resort & Tropical Hotel Manaus & Norte/AM & Gerente Geral & 75 \\
\hline Resort & Vila Galé Cumbuco & Nordeste/CE & Relações Públicas & 61 \\
\hline Resort & Zagaia Eco-Resort & Centro-oeste/MS & Geral Geral & 89 \\
\hline
\end{tabular}

Fonte: Elaborado pelos autores

Também, adotando por base as organizações presentes nas categorias de hospedagem com maior número de Unidades de Habitação (UHS): hotéis, pousadas e resorts, vale destacar que foi efetuada a aplicação do método de agrupamento não hierárquico por partição denominado centroide, envolvendo as seguintes variáveis disponibilizadas no sistema CADASTUR: número de unidades de habitação (UHS), número de leitos, número de UHS para cadeirantes, número de UHS com acomodação de cão guia e número de UHS com telefones para surdos. Esse método de agrupamento foi escolhido devido as características descritivas presentes no objetivo geral deste estudo, sendo os clusters interpretados com a utilização do teste de igualdade de variâncias (teste de Levene) e outros testes post-hoc, que verificaram diferenças significativas entre as variáveis utilizadas: one way ANOVA e Bonferroni.

\section{APRESENTAÇÃO E DISCUSSÃO DOS RESULTADOS}

Neste tópico são apresentados e discutidos os resultados encontrados por meio da aplicação do método utilizado nesta pesquisa. Especificamente, são demonstrados como resultados uma síntese de informações sobre a dimensão setorial dos estabelecimentos turísticos brasileiros, bem como, indicadores estruturais das redes de hospedagem analisadas com maior número de Unidades Habitacionais (UHS) (conteúdo do banco de dados e entrevistas).

\subsection{Dimensão Setorial dos Estabelecimentos Turísticos Brasileiros}

De acordo com dados do Ministério do Turismo (CADASTUR, 2014), o turismo receptivo no Brasil registrou o ingresso de 5,2 milhões de turistas estrangeiros em 2012, um patamar considerado baixo, quando comparado com outros países como França (76,8 milhões), Estados Unidos 
(59,7 milhões), China (55,7 milhões) e Espanha (52,7 milhões). Por outro lado, os grandes eventos internacionais realizados no Brasil, como a Copa das Confederações (2013), a Copa do Mundo de Futebol (2014), trouxeram a perspectiva de um aumento expressivo desse ingresso, bem como a expansão do turismo nacional.

O crescimento esperado da demanda turística vem a exigir, em contrapartida, uma infraestrutura compatível com essa demanda, em especial no que concerne à melhoria dos serviços turísticos, que abrangem transportes turísticos (transporte aéreo, transportes rodoviários intermunicipal, interestadual e internacional, serviços de excursões, serviços de transfer, entre outros), locadoras de automóveis, agências de viagens e serviços de hospedagem e de alimentação.

Os serviços de hospedagem encontram-se no último elo da cadeia dos serviços turísticos e configuram-se como um dos mais importantes, pois representam a base de permanência temporária do turista, que, de uma forma geral, busca encontrar a extensão de sua residência, ou seja, serviços que reproduzam o mesmo padrão de conforto de sua residência habitual.

Em termos de organização das atividades econômicas que configuram os serviços empresariais não financeiros, os serviços de hospedagem inserem-se no conjunto dos serviços prestados às famílias e, nesse conjunto, destaca-se como o segundo maior gerador de postos de trabalho nesse setor, com 300 mil pessoas ocupadas em 2012 (IBGE, 2014). Considerando-se os dados por empresa, os serviços de hospedagem são os mais intensivos em mão de obra, com uma taxa de ocupação de 12 pessoas ocupadas por empresa, contra a taxa de sete, registrada nos serviços prestados às famílias.

Conforme dados do IBGE (2014) as quatro maiores Regiões Metropolitanas das Capitais, em termos de rede de hospedagem, foram responsáveis por $40,6 \%$ do total de estabelecimentos, $46,3 \%$ das unidades habitacionais, e 44,2\% da capacidade total de hóspedes. São elas:

- Região Metropolitana de São Paulo, com 1323 estabelecimentos (17,7\% do total), 68 858 unidades habitacionais (21,0\% do total) e capacidade total de 146381 hóspedes $(19,7 \%$ do total);

- Região Metropolitana do Rio de Janeiro, com 609 estabelecimentos (8,1\% do total), 38 565 unidades habitacionais ( $11,8 \%$ do total) e capacidade total de 83130 hóspedes (11,2\% total);

- Região Metropolitana de Belo Horizonte, com 589 estabelecimentos (7,9\% do total), 21 809 unidades habitacionais $(6,7 \%$ do total) e capacidade total de 48393 hóspedes (6,5\% total); e

- Região Metropolitana de Salvador, com 516 estabelecimentos (6,9\% do total), 21591 unidades habitacionais (6,6\% do total) e capacidade total de 50158 hóspedes (6,8\% total).

Ainda, de acordo com dados do IBGE (IBGE, 2014), os estabelecimentos de hospedagem localizados nas Regiões Metropolitanas das Capitais brasileiras são constituídos predominantemente por hotéis (inclusive hotéis históricos, resorts e hotéis-fazenda), que respondem por 46,9\% do total, seguidos por motéis, com $24,8 \%$, e pousadas, com $20,0 \%$. Seguem-se os estabelecimentos com 
menor expressividade, como apart-hotéis/flats, com 3,2\%, pensões de hospedagem (inclusive estabelecimentos do tipo cama e café ou pousadas domiciliares), com 2,7\%, albergues turísticos, com 1,4\%, e outros (campings, dormitórios, hospedarias, entre outros.), com 1,0\%.

Em síntese, tem-se que a infraestrutura de hospedagem brasileira apresenta um razoável quantitativo em termos de unidades habitacionais e quantidade de leitos. Também, apresenta um crescente fluxo turístico em seus aeroportos, destacando-se os estados de São Paulo, Rio de Janeiro e Minas Gerais. Porém, no que se refere a qualidade da infraestrutura de serviços de hospedagem comercializados, a falta de uniformidade entre os empreendimentos, é um aspecto relevante nesse setor.

\subsection{Redes de Hotéis}

Com base na verificação das semelhanças dos serviços oferecidos em 4158 hotéis analisados, notou-se predominância dos seguintes serviços: restaurante, bar e elevador. Essa relação de serviços definiu a rede com densidade de 0,08 , ou seja, do total de pontos comuns possíveis de serem encontrados entre os hotéis, apenas $8 \%$ se fazem presente entre eles. Ainda, com base na identificação de subgrupos, notou-se a existência de 68 subgrupos com o mínimo de três organizações. Isto demonstra que apesar dos serviços oferecidos identificados como semelhantes constituírem uma necessidade para atividade hoteleira, o compartilhamento de características de estrutura é restrito para poucos hotéis.

Os hotéis que apresentaram centralidade de entrada e saída na rede identificada foram: Sauipe Park e Centro de Turismo de Praia Formosa. O primeiro localizado no estado da Bahia e o segundo no Espírito Santo. Por sua vez, a centralidade de proximidade foi verificada no Rio Othon Palace Hotel, localizado no Rio de Janeiro. Vale mencionar que esse hotel faz parte de uma rede hoteleira internacional, com hotéis dotados de uma infraestrutura utilizada em todo o mundo. Por fim, identificou-se ainda a centralidade de intermediação para o Sauipe Park. A tabela a seguir apresenta os valores encontrados.

Tabela 1 - Indicadores Estruturais da rede de hotéis

\begin{tabular}{cc}
\hline Indicadores Estruturais & Resultados \\
\hline Tamanho da rede & 4158 \\
Densidade da rede & 0,08 \\
Quantidade de Subgrupos & 68 (três organizações) \\
Serviços semelhantes & Restaurante, bar e elevador \\
Centralidade Grau de Entrada & Sauipe Park e Centro de Turismo de Praia Formosa \\
Centralidade Grau de Saída & Sauipe Park e Centro de Turismo de Praia Formosa \\
Centralidade Proximidade & Rio Othon Palace Hotel \\
Centralidade Intermediação & Sauipe Park \\
\hline
\end{tabular}

Fonte: Tratamento de dados

$\mathrm{Na}$ análise de agrupamento, foram identificados três clusters. O primeiro cluster formado por 1531 hotéis $(36,8 \% l)$, o segundo cluster formado por 361 hotéis $(8,7 \%)$ e o terceiro cluster formado por 2266 hotéis (54,5\%), totalizando 654 hotéis. Com base nestes três clusters, foi verifi- 
cado se as diferenças entre as variáveis utilizadas para o agrupamento tinham significado estatístico (ou ocorreram por acaso), caracterizando os grupos por meio das variáveis que mais contribuíram para esse efeito.

Dessa maneira, ao ser realizado o teste de igualdade de variâncias (teste de Levene), os resultados demonstram que todas as variáveis (Unidades de Habitação - UHS, Leitos, UHS para cadeirantes, UHS com acomodação de cães guias e UHS com telefones para surdos) se mostraram significativas a 0,001 . Os mesmos resultados também foram encontrados no teste ANOVA, uma vez que a igualdade de variância já tinha sido encontrada no teste anterior. No entanto, ao ser realizado o teste Bonferroni para as variáveis que tinham sido verificadas com igualdade de variância, foi encontrado que nos clusters dois e três, a variável 'UHS com telefones para surdos', não apresentou igualdade significativa. Isto significa que essa variável não deve ser utilizada para comparar esses clusters. Uma das possíveis razões capaz de explicar a diferenciação entre esses grupos está na localização da maioria dos empreendimentos: São Paulo, Rio de Janeiro e Bahia, que conforme identificado na pesquisa documental, respondem por quase $43 \%$ da capacidade hoteleira brasileira.

\subsection{Redes de Pousadas}

Com base na verificação das semelhanças dos serviços oferecidos em 1823 pousadas analisadas, notou-se semelhança nos seguintes serviços: disponibilização de informações, folhetos turísticos e banheiros sociais. Esta relação de serviços definiu uma rede com densidade de 0,17, ou seja, do total de pontos comuns possíveis de ser encontrados entre as pousadas, apenas $17 \%$ se fazem presente entre elas. Esta densidade, apesar de baixa, é superior aquela encontrada na rede hoteleira. Isto demonstra características de uma infraestrutura de organizações mais parecidas em termos de serviços oferecidos nessa rede, apesar de apenas dois pontos semelhantes verificados.

$\mathrm{Na}$ identificação de subgrupos, notou-se a existência 74 subgrupos com o mínimo de três organizações, comprovando assim, a semelhança de infraestrutura acima verificada. As pousadas que apresentaram centralidade de entrada e saída na rede foram: Lemos Passo e Pousada Sauipe. Por sua vez, a centralidade de proximidade foi verificada em Pousada das Piabas e a de intermediação, Pousada Sauipe. A tabela a seguir relaciona os valores encontrados.

Tabela 2 - Indicadores estruturais da rede de pousadas

\begin{tabular}{cc}
\hline Indicadores Estruturais & Resultados \\
\hline Tamanho da rede & 1823 \\
Densidade da rede & 0,17 \\
Quantidade de Subgrupos & 74 subgrupos (três organizações) \\
Serviços semelhantes & Disponibilização de informações e folhetos turísticos, banheiros sociais \\
Centralidade Grau de Entrada & Pousada Sauipe e SESC Pousada de Araxá \\
Centralidade Grau de Saída & Pousada Sauipe e SESC Pousada de Araxá \\
Centralidade Proximidade & Pousada Silene \\
Centralidade Intermediação & Sesc Pousada de Araxá \\
\hline
\end{tabular}

Fonte: Tratamento de dados 
$\mathrm{Na}$ análise de agrupamento, conforme era esperado com base nos dados anteriores de homogeneidade dos empreendimentos, foi identificado apenas um grande cluster. Dessa maneira, não foi possível realizar os testes de igualdade de variância efetuados na rede anterior. No entanto, são analisadas as variáveis de forma descritiva mensuradas neste cluster. Vale mencionar que apesar de se ter um grande grupo de organizações semelhantes, favorecendo com isso uma estrutura de cooperação, nota-se que em nenhuma pousada foi detectada UHS com acomodação com cães guias ou com telefones para surdo. Isto demonstra a estrutura precária das pousadas brasileiras. A tabela a seguir apresenta estas informações:

Tabela 3 - Dados descritivos do cluster da rede de pousadas

\begin{tabular}{cc}
\hline Variáveis & Resultados \\
\hline Total de Unidades de Habitação (UHS) & 29989 \\
Total de Leitos & 80766 \\
Total de UHS para cadeirantes & 1274 \\
Total de UHS com cães guias & 213 \\
Total de UHS com telefone para surdos & 14 \\
Total de Organizações que atendem em inglês & 242 \\
\hline
\end{tabular}

Fonte: Tratamento de dados

Com base nos dados descritivos obtidos do único cluster formado na rede de pousadas, tem-se uma análise da média e do desvio padrão de cada variável mensurada. Nota-se que a maior média está no número de leitos (44,32), sendo a segunda, no número de Unidades de Habitação $(16,45)$. Conforme já demonstrada a baixa existência de UHS com acomodação para cães guias e telefones para surdos na rede de pousadas, tem-se também, um baixo número de UHS com acomodação para cadeirantes, corroborando com a precariedade da infraestrutura. Essa situação pode ser explicada no maior direcionamento de investimentos de infraestrutura para a rede de hotéis e resorts, deixando as pousadas em segundo plano.

\subsection{Redes de Resorts}

Os resorts, dentre as três redes de hospedagem identificadas, foi aquela que deteve a menor quantidade de organizações envolvidas, no entanto, a maior diversidade e complexidade de análise por contemplar um mercado diferenciado: o mercado do turismo de luxo. Para Coriolano e Almeida (2007), os resorts são meios de hospedagens com configurações espaciais elitizadas, localizadas preferencialmente em áreas naturais preservadas e, muitas vezes, distantes de áreas urbanizadas. Para esses autores, os resorts representam "um mundo isolado, utilizando-se e de uma variedade de estratégias para reter o turista, sem dar-lhes chances de sair desses ambientes, para divertimentos e consumos fora das dependências" (Coriolando \& Almeida, 2007, p.4). Silva e Melo (2010, p.36) destacam que "o diferencial dos resorts em relação aos hotéis e as pousadas é a sua localização na forma de enclaves que o grupo econômico denomina paradisíaco e tem, como frequentadores, clientes de alto poder aquisitivo, dispostos a pagar pelo lazer de luxo". 
Com base na verificação das semelhanças dos serviços oferecidos em 109 resorts, notou-se semelhança em todos os serviços pesquisados na grande maioria dos empreendimentos: estacionamento, restaurante, bar, manobrista, disponibilização de informações e folhetos turísticos, banheiros sociais em áreas comuns e elevador. Esta relação de serviços definiu uma rede com densidade de 0,84 , ou seja, do total de pontos comuns possíveis de ser encontrados entre os resorts, $84 \%$ se fazem presente. Ainda, com base na identificação de subgrupos, notou-se a existência de 46 com o mínimo de três organizações. Isto demonstra que essa rede de hospedagem interage mais que as outras duas pesquisadas, visto a quantidade de resorts existentes.

Os resorts que apresentaram centralidade de entrada e saída na rede identificada foram: Grand Palladium Imbassai e IberoStar. Ambos localizados no estado da Bahia. A centralidade de proximidade foi verificada no Bourbon Atibaia Convention, localizado em São Paulo. Por fim, identificou-se ainda a centralidade de intermediação para o Praia do Forte Ecoresort, localizado na Bahia. A tabela a seguir relaciona os valores encontrados.

Tabela 4 - Indicadores estruturais da rede de Resorts

\begin{tabular}{cc}
\hline Indicadores Estruturais & Resultados \\
\hline Tamanho da rede & 109 \\
Densidade da rede & 0,84 \\
Quantidade de Subgrupos & 46 (três organizações) \\
Serviços semelhantes & Todos os pesquisados \\
Centralidade Grau de Entrada & Grand Palladium Imbassai e IberoStar \\
Centralidade Grau de Saída & Grand Palladium Imbassai e IberoStar \\
Centralidade Proximidade & Bourbon Atibaia Convention \\
Centralidade Intermediação & Praia do Forte Ecoresort \\
\hline
\end{tabular}

Fonte: Tratamento de dados

Em termos descritivos, os resultados encontrados apontam para a existência de um total de 18593 UHS nos resorts brasileiros. Esse montante representa 42487 leitos. Apesar desse tipo de categoria de hospedagem ser referência em termos qualitativos, são encontrados baixos números de UHS para cadeirantes (575), UHS com acomodação para cães guias (122) e UHS com telefone para surdos (86). No entanto, todos os resorts atendem em inglês. A tabela abaixo apresenta os valores encontrados.

Tabela 5 - Dados descritivos da rede de resorts

\begin{tabular}{cc} 
Variáveis & Resultados \\
\hline Total de Unidades de Habitação (UHS) & 18593 \\
Total de Leitos & 42487 \\
Total de UHS para cadeirantes & 575 \\
Total de UHS com cães guias & 122 \\
Total de UHS com telefone para surdos & 86 \\
Total de Organizações que atendem em inglês & 109 \\
\hline
\end{tabular}

Fonte: tratamento de dados

$\mathrm{Na}$ análise de agrupamentos, foram identificados dois clusters. O primeiro cluster formado por 83 resorts $(76,2 \%)$ e o segundo cluster formado por 26 resorts $(23,8 \%)$, totalizando 109 resorts. 
Conforme foi efetuado com a rede de hotéis, com base nestes dois clusters, foi verificado se as diferenças entre as variáveis utilizadas para o agrupamento tinham significado estatístico (ou ocorreram por acaso), caracterizando os grupos por meio das variáveis que mais contribuíram para esse efeito.

Dessa maneira, ao ser realizado o teste de igualdade de variâncias (teste de Levene), os resultados demonstram que todas as variáveis (Unidades de Habitação - UHS, Leitos, UHS para cadeirantes, UHS com acomodação de cães guias e UHS com telefones para surdos) se mostraram significativas a 0,001 . Os mesmos resultados também foram encontrados no teste ANOVA, uma vez que a igualdade de variância já tinha sido encontrada no teste anterior. No Bonferroni para as variáveis que tinham sido verificadas com igualdade de variância, foi encontrado que nos clusters dois, as variáveis 'UHS com telefones para surdos' e 'UHS com acomodações para cães guias', apresentaram igualdade significativa em sua variância $(p<0,001)$, enquanto no 'cluster um' essa mesma condição não foi verificada: UHS com telefones para surdos p> 0,641 e 'UHS com acomodações para cães guias $p>0,487$. A figura abaixo apresenta os clusters encontrados.

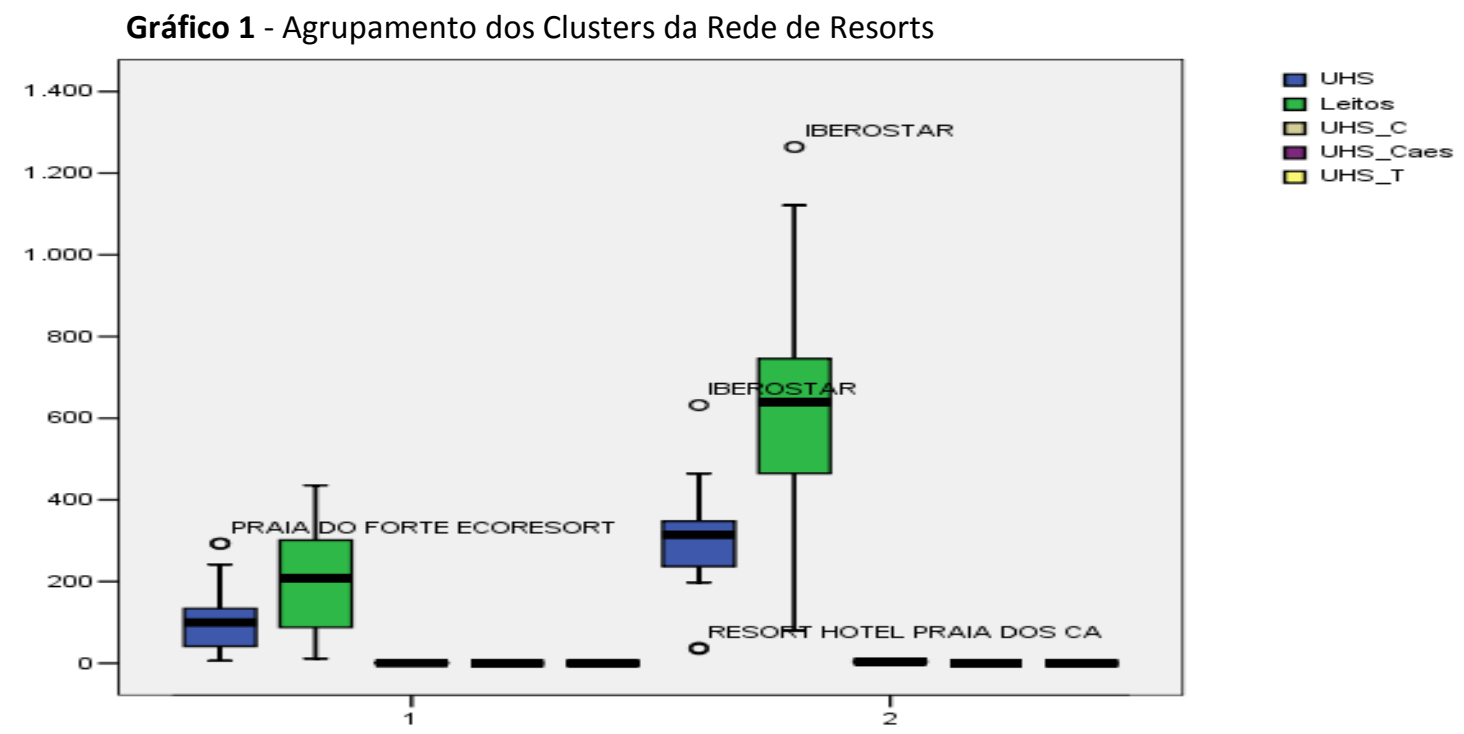

Fonte: tratamento de dados

Este resultado encontrado na análise de agrupamentos demonstra a existência de dois grupos de resorts com características e enfoques diferenciados na prestação de serviços. O primeiro grupo com características tradicionais do mercado de luxo, enfatizando o luxo da infraestrutura física como o diferencial do negócio. O segundo grupo, além de enfatizar características tradicionais do mercado do luxo (infraestrutura física, dimensão, localização, entre outras), enfatiza também a diversidade de serviços oferecidos no atendimento de segmentos de mercados de alto padrão inexplorados no Brasil, como por exemplo, pessoas de alto poder aquisitivo com necessidades especiais.

De acordo com dados do Ministério do Turismo (CADASTUR, 2014), embora os investimentos na infraestrutura turística brasileira de forma diferenciada sejam ainda pouco expressivos, no 
médio e longo prazo, apontam para uma possível redução das desigualdades regionais de desenvolvimento. Obras ligadas a logística portuária e ferroviária, projeto de transposição do São Francisco, da refinaria em Pernambuco, Olimpíadas, entre outros proporcionam novas oportunidades de investimentos privado e público de suporte aos resorts. O conjunto destes fatores possibilita para o segundo grupo de resorts verificado, condições externas favoráveis para aumento da participação no mercado de turismo de luxo internacional, proporcionando o desenvolvimento econômico dos estados brasileiros.

\section{COMPARAÇÃO DAS REDES ANALISADAS}

$\mathrm{Na}$ análise comparativa das três redes de hospedagem identificadas, alguns resultados merecem destaque: o primeiro ponto de destaque compreende as medidas de densidade das redes. Com base neste indicador, a rede com o menor número de organizações, formada por 109 resorts, foi identificada com a de maior densidade nos serviços turísticos pesquisados (densidade igual a 0,84). Vale ressaltar que essa rede, de forma específica, representa um conceito padrão de luxo em hotelaria. Portanto, já era esperado que as organizações que dela fazem parte apresentassem uma estrutura de serviços parecida, favorecendo com isso, maior densidade.

No entanto, apesar desta semelhança entre os empreendimentos, os subgrupos de resorts analisados apresentaram pontos de diferenciação na venda de novos produtos turísticos, roteiros e de nichos de mercado não abordados por grandes complexos internacionais neste setor. Em alguns estados brasileiros, Santa Catarina, por exemplo, empreendimentos encontram alternativas para sua inclusão em roteiros turísticos locais para o aproveitamento das artes, gastronomias, folclores, atrativos naturais e culturais, transformando o potencial regional em produto ou oferta turística. Estes subgrupos, adaptado as condições de viabilidade dos empreendimentos, influenciam e alavancam a infraestrutura de hospedagem de outros empreendimentos menores, tais como: pequenas pousadas e hospedagens residenciais, localizados no contexto regional de inserção dos resorts.

Hammerseley (2014) ao analisarem as redes de turismo internacionais com técnicas de análise de redes sociais encontraram resultados de densidade semelhantes aos verificados na rede de hospedagem de resorts no Brasil. Para esse autor, o mercado turístico de empreendimentos de alto luxo apresenta uma estrutura bastante densa em sua rede de relacionamentos e de serviços prestados. No entanto, a diferença dos principais destinos internacionais comparados com o Brasil é que nesses primeiros, de acordo com esse autor mencionado, os relacionamentos estabelecidos por resorts englobam o desenvolvimento de redes de serviços turísticos correlatos, entre eles: agências de viagem, centro de convenções, agência de turismo, parques temáticos, restaurantes, bares, casas de espetáculos, entre outros. O que favorece, de maneira uniforme, o desenvolvimento desse setor em várias regiões do mundo.

O segundo ponto de destaque compreende a alta homogeneidade verificada nas redes de pousadas, quando comparadas com as demais (hotéis e resorts). Nesses empreendimentos, a falta 
de diferenciação dos produtos turísticos oferecidos se configura como uma barreira para o desenvolvimento da infraestrutura existente nos estados brasileiros. Conforme é verificado em Zeher (2014), as pousadas, assim como os hotéis precisam estar atentas na exploração de novas possibilidades da região onde estão instaladas, tais como: elementos históricos, esportes radicais, as frutas típicas, a culinária tradicional, lazer praia ou lazer montanha, o ambiente de fazenda, clima de montanha. No entanto, a realidade das pousadas no Brasil parecem não estar atentas a essa situação.

Por representar um segmento de hospedagem de menor valor econômico no custo da diária, o número de pousadas identificadas indica um excesso de oferta no mercado brasileiro, pelo lançamento de vários empreendimentos voltados para um mesmo segmento, dotados com os mesmos serviços oferecidos. Apesar das possibilidades de crescimento dessa categoria de hospedagem ser real, torna-se necessário que os gestores destes empreendimentos identifiquem novos segmentos de mercado, como por exemplo, uma das opções poderia ser hospedagem para mochileiros, que ofereçam conforto aliado ao preço acessível. O turismo de lazer ou de negócios também é uma atividade em expansão para esse segmento como ocorre em outros lugares do mundo (Zimanyi \& Kozar, 2014).

Como um último ponto de destaque na comparação entre as três redes, tem-se a localização geográfica dos empreendimentos denominados como atores centrais nesta pesquisa. Nota-se que os estados de São Paulo, Rio de Janeiro e Bahia se constituem como locos da maioria dos empreendimentos caracterizados como centrais (grau, proximidade e intermediação). Os possíveis motivos que justificam esta condição são os papéis representados pelas cidades turísticas em seu entorno, constituindo-se nos principais destinos turísticos do Brasil, com o maior volume aéreo de desembarque de passageiros (nacionais e internacionais). Vale destacar que o carnaval é um dos grandes atrativos do Rio de Janeiro e da Bahia, principalmente nas cidades do Rio de Janeiro e Salvador, justificando com isso, a implantação das maiores estruturas de hospedagem das três redes pesquisadas nesses lugares. Além disso, o turismo de negócios do estado de São Paulo contribui para a concentração de uma estrutura de serviços de hospedagem de diferentes padrões nesse estado.

\section{CONSIDERAÇÕES FINAIS}

Este trabalho objetivou identificar as redes de hospedagem brasileiras por meio de indicadores da infraestrutura de serviços comercializados nos estabelecimentos turísticos que formam essas redes. Por isso, com base na leitura dos indicadores estruturais oriundos na Análise de Redes Sociais, foram analisadas semelhanças entre os serviços oferecidos (estacionamento, restaurante, bar, manobrista, disponibilização de informações e folhetos turísticos, banheiros sociais em áreas comuns e elevador) em 6119 empreendimentos nas seguintes categorias de hospedagem: hotéis, pousadas e resorts. Estas redes também foram agrupadas em clusters por meio das seguintes vari- 
áveis: total de Unidades de Habitação - UHS, total de leitos, UHS com acomodação para cadeirantes, cães guias e telefone para surdos.

Os resultados indicaram, de um modo geral, que as três redes identificadas possuem diferenças significativas em termos da infraestrutura de hospedagem e serviços oferecidos. Além disso, notou-se ainda que a rede de hospedagem de resorts apresenta uma estrutura de serviços mais densa quando comparada com as demais, porém contendo alta complexidade e diversidade de serviços turísticos oferecidos. Ainda de forma ampla, a infraestrutura de hospedagem brasileira apresenta um razoável quantitativo em termos de unidades habitacionais e quantidade de leitos que são fomentados por um crescente fluxo turístico em seus aeroportos, destacando-se os estados de São Paulo, Rio de Janeiro e Bahia, como os destinos principais. Porém, no que se refere a qualidade da infraestrutura de hospedagem, a falta de uniformidade entre os empreendimentos e os baixos investimento em sistemas de qualidade, são aspectos relevantes nesse setor.

De forma específica, foram identificadas particularidades entre as redes na aplicação da técnica de agrupamento utilizada: na rede de hotéis foram identificados três clusters, na rede de pousadas um cluster e na rede de resorts dois clusters. Dentre as variáveis utilizadas para o agrupamento destes empreendimentos turísticos, todas se mostraram significativas a um nível de 0,001, exceto: 'número de UHS com acomodação de cão guia' e 'número de UHS com telefones para surdos', pela ausência deste tipo de infraestrutura na maioria das organizações presentes nas redes identificadas.

O estudo proposto por Ivanov e Webster (2011) demonstra que o processo de superação de desafios vivenciados por redes interorganizacionais no setor de turismo faz que os participantes modifiquem com sucesso as formas de relacionamentos estabelecidos, buscando novas oportunidades no mercado. Nesta direção, notou-se nas três redes pesquisadas a necessidade iminente de compartilhamento de informações sobre segmentos de mercados atendidos e investimentos. Principalmente, na integração de serviços entre as organizações existentes. Isso aponta a principal contribuição teórica deste estudo ao detalhar as principais características da infraestrutura de hospedagem existente no Brasil, sugerindo um cenário para novas pesquisas sobre relacionamentos interorganizacionais que podem se estruturar de maneira estratégica no turismo brasileiro.

São sugeridos estudos futuros sobre a análise comparativa de indicadores estruturais presentes em outras regiões geográficas brasileiras e segmentos de serviço turístico. Além disso, é sugerida a verificação da influência externa que relacionamentos de organizações presentes em diferentes setores econômicos e diferentes níveis de análise possuem no processo de desenvolvimento das redes situadas no setor turístico brasileiro.

\section{REFERÊNCIAS}

Bae, J. \& Gargiulo, M. (2004). Partner substitutability, alliance network structure, and firm profitability in the telecommunications industry. Academy of Management Journal, v.47, n.6, p.843-859. 
Balestrin, A., Vershoore, J. R. \& Reyes-Júnior. (2010). O Campo de Estudos sobre Redes de Cooperação Interorganizacional no Brasil. Revista de Administração Contemporânea, Curitiba, v. 14, n. 3, art. 4, p. 458-477.

Bock, I. A. A. \& Macke, J. (2014). The Social Capital and the Development of Collaborative Networks in the Tourism Sector: a Case Study on The Grupo Gestor do Turismo Rural do Rio Grande do Sul (Rural Tourism Steering Group) - RS, Brazil. Revista Brasileira de Pesquisa em Turismo, São Paulo, v. 8, n. 1, p. 23-41.

Cadastur. Sistema De Cadastro De Pessoas Físicas E Jurídicas Que Atuam No Setor Do Turismo. Disponível em: <cadastur.turismo.gov.br> Acesso em 14 mai. 2014.

Carmona, V. C., Costa, B. K. \& Ribeiro, H. C. M. (2014). Competitividade em Turismo: estudo da produção científica internacional. Revista Brasileira de Pesquisa em Turismo, São Paulo, v. 8, n. 2, p. 201-221.

Coriolano, L. N. \& Almeida, H. M. (2007). O turismo no Nordeste Brasileiro. Revista eletrônica de Geografia y Ciencias Sociales, v.11, n.245.

Everett, M. G. \& Borgatti, S. P. (2005). Extending Centrality In: Models and Methods in Social Network Analysis. New York: Cambridge Press.

Freeman, L. C. (1979). Centrality in Social Networks: Conceptual clarification. Social Networks, v.1, p.215239.

Gibbons, D. E. (2004). Network structure and innovation ambiguity effects on diffusion in dynamic organizational fields. Academy of Management Journal, v.47, n.6.

Hammersley, L.A. (2014). Volunteer tourism: building effective relationships of understanding. Journal of Sustainable Tourism, Clevedon, v. 22, n. 6, p. 855.

Ibge. Instituto Brasileiro De Geografia E Estatística. Disponível em: <ibge.gov.br> Acesso em 12 fev. 2014.

Ivanov, S. \& Webster, C. (2011). Tourism's Contribution to Economic Growth: A Global Analysis for the First Decade of the Millenium. SSRN Working Paper Series, Rochester 11.

Kwon, S., Kim, S. \& Yi-Kook, J. (2011). Social Network Analysis of Stakeholders in Green Tourism. Studies in Regional Science, v.39, n.3, p. 767-781.

Martes, A. C. B. \& colaboradores. (2006). Fórum - Redes Sociais e Interorganizacionais. Revista de Administração de Empresas, v.46, n.3, p.10-15.

Nelson, R. (1984). O uso da Análise de Redes Sócias no estudo das estruturas organizacionais. Revista de Administração de Empresas, v.24, n.4, p.150-157. 
Pinto, A. M. G. \& Junqueira, L. A. P. (2009). Relações de poder em uma rede do terceiro setor: um estudo de caso. Revista de Administração Pública, v.43, n.5, p.1091-1116.

Pinto, H. \& Cruz, A. R. (2012). Structuring a Knowledge-based Maritime Cluster: Contributions of Network Analysis in a Tourism Region/Estructuración de un Clúster Marítimo basado en Conocimiento: Aportaciones del análisis de redes en una región de turismo. Revista de Estudios Regionales, Cadiz, n. 95, p. 101-118.

Rossoni, L., Hocayen-da-Silva, A. \& Ferreira Jr. (2008). Aspectos Estruturais da Cooperação entre Pesquisadores no Campo de Ciência e Tecnologia: análise das redes entre instituições no Brasil. Revista de Administração Pública, v.42, n.6.

Scott, J. (2000) Social Network Analysis: a handbook. 2 ed., London: Sage Publications.

Seidman, S. B. (1983). Network Structure and Minimum Degree. Social Networks, v.5, p.269-287.

Zehrer, A. (2014) Leadership networks in destinations.Tourism Review of AIEST - International Association of Scientific Experts in Tourism, Bingley, v. 69, n. 1, p. 59-73, 2014.

Zimanyi, K. \& Kozar, L. (2014). A New Form of On-line Sales in Commerce and Tourism: Trends, Advantages and Risks. Journal of American Business Review, Cambridge., New York, v. 2, n. 2, p. 104-110.

Wasserman, S. \& Faust, K. (1994). Social Network Analysis: Methods and Applications. New York: Cambridge Press.

Wu, L., Zhang, J., Fujiwara, A. \& Chikaraishi, M. (2012). Analysis of Tourism Generation Incorporating the Influence of Constraints Based on a Scobit Model. Asian Transport Studies, v.2, n.1, 2012.

Artigo recebido em: 29/06/2014. Artigo aprovado em: 13/08/2015. 